EGU21-7626, updated on 01 Feb 2022

https://doi.org/10.5194/egusphere-egu21-7626

EGU General Assembly 2021

(c) Author(s) 2022. This work is distributed under

the Creative Commons Attribution 4.0 License.

\title{
Snow microstructure on sea ice: Importance for remote sensing applications
}

\author{
Amy R. Macfarlane ${ }^{1}$, Stefanie Arndt ${ }^{2}$, Ruzica Dadic ${ }^{3}$, Carolina Gabarró ${ }^{4}$, Bonnie Light ${ }^{5}$, Mallik \\ Mahmud $^{6}$, Reza Naderpour ${ }^{1}$, Randall Scharien ${ }^{7}$, Madison Smith ${ }^{5}$, Gunnar Spreen ${ }^{8}$, Julienne \\ Stroeve ${ }^{9,10}$, Aikaterini Tavri ${ }^{7}$, David N. Wagner ${ }^{1,11}$, and Martin Schneebeli ${ }^{1}$ \\ ${ }^{1}$ WSL Swiss Federal Institute for Forest, Snow and Landscape Research \\ ${ }^{2}$ Alfred Wegener Institute, 27570 Bremerhaven, Germany \\ ${ }^{3}$ Antarctic Research Centre, Victoria University of Wellington \\ ${ }^{4}$ BEC \& Institute of Marine Science, CSIC, Barcelona, Spain \\ ${ }^{5}$ Applied Physics Laboratory, University of Washington, Seattle, WA, USA \\ ${ }^{6}$ University of Calgary, AB Canada \\ ${ }^{7}$ University of Victoria, BC Canada \\ ${ }^{8}$ University of Bremen, Institute of Environmental Physics, 28359 Bremen, Germany \\ ${ }^{9}$ University of Manitoba, Winnipeg, MB, R3T 2N2 \\ ${ }^{10}$ UCL Earth Sciences, Bloomsbury, London WC1E 6BT \\ ${ }^{11}$ CRYOS, School of Architecture, Civil and Environmental Engineering, EPFL, 1015 Lausanne, Switzerland
}

Snow plays a key role in interpreting satellite remote sensing data from both active and passive sensors in the high Arctic and therefore impacts retrieved sea ice variables from these systems ( e.g., sea ice extent, thickness and age). Because there is high spatial and temporal variability in snow properties, this porous layer adds uncertainty to the interpretation of signals from spaceborne optical sensors, microwave radiometers, and radars (scatterometers, SAR, altimeters). We therefore need to improve our understanding of physical snow properties, including the snow specific surface area, snow wetness and the stratigraphy of the snowpack on different ages of sea ice in the high Arctic.

The MOSAiC expedition provided a unique opportunity to deploy equivalent remote sensing sensors in-situ on the sea ice similar to those mounted on satellite platforms. To aid in the interpretation of the in situ remote sensing data collected, we used a micro computed tomography (micro-CT) device. This instrument was installed on board the Polarstern and was used to evaluate geometric and physical snow properties of in-situ snow samples. This allowed us to relate the snow samples directly to the data from the remote sensing instruments, with the goal of improving interpretation of satellite retrievals. Our data covers the full annual evolution of the snow cover properties on multiple ice types and ice topographies including level first-year (FYI), level multi-year ice (MYI) and ridges.

First analysis of the data reveals possible uncertainties in the retrieved remote sensing data products related to previously unknown seasonal processes in the snowpack. For example, the 
refrozen porous summer ice surface, known as surface scattering layer, caused the formation of a hard layer at the multiyear ice/snow interface in the winter months, leading to significant differences in the snow stratigraphy and remote sensing signals from first-year ice, which has not experienced summer melt, and multiyear ice. Furthermore, liquid water dominates the extreme coarsening of snow grains in the summer months and in winter the temporally large temperature gradients caused strong metamorphism, leading to brine inclusions in the snowpack and large depth hoar structures, all this significantly influences the signal response of remote sensing instruments. 